\title{
Entamoeba histolytica and amoebic liver abscess in northern Sri Lanka: a public health problem
}

\author{
Tharmegan Tharmaratnam ${ }^{1,2^{*}}$ (D), Thirunavukarasu Kumanan ${ }^{3,4}$, Mina Amin Iskandar ${ }^{1,2}$, Katrina D'Urzo', \\ Prasaanthan Gopee-Ramanan 5,6, Mayura Loganathan 7,8, Tyler Tabobondung9,10, Taylor Anthony Tabobondung ${ }^{11}$, \\ Seyon Sivagurunathan ${ }^{10,12}$, Mitul Patel $^{2}$ and lqdam Tobbia ${ }^{1,2,13}$
}

\begin{abstract}
Entamoeba histolytica (E. histolytica) is a facultative protozoan parasite implicated in amoebic liver abscesses (ALA), the most common extraintestinal manifestation of this infection. E. histolytica is endemic to sub-tropical and tropical countries and has been a major public health concern in northern Sri Lanka (SLK) for the last three decades. This has been attributed to a multitude of factors such as poor sanitation, hygiene, male sex, middle age, overcrowding, unsanitary practices in the production of indigenous alcoholic beverages, and alcohol consumption. Additionally, while rates of $E$. histolytica have declined substantially throughout the rest of the island, largely due to better infrastructure, it remains pervasive in the northern peninsula, which is generally less developed. Infection arises primarily from fecal-oral transmission through the consumption of contaminated drinking water containing cysts. Upon ingestion, cysts multiply into trophozoites and colonize the host colonic mucosa using lectin and cysteine proteases as virulence factors, leading to host invasion. Symptoms occur along a spectrum, from asymptomatology, to pyrexia, abdominal cramping, and amoebic dysentery. Colonization of the colon results in the formation of distinct flask-shaped ulcers along the epithelium, and eventual penetration of the lamina propria via the production of matrix metalloproteinases. ALA then develops through trophozoite migration via the mesenteric hepatic portal circulation, where microabscesses coalesce to form a single, large right-lobe abscess, commonly on the posterior aspect. The progression of infection to invasive disease is contingent on the unique interplay between host and pathogen factors, such as the strength of host-immunity to overcome infection and inherent pathogenicity of the Entamoeba species. As a preventable illness, $E$. histolytica complications such as ALA impose a significant burden on the healthcare system. This mini-review highlights epidemiological trends, risk factors, diagnostic modalities, treatment approaches, and opportunities for prevention of $E$. histolytica-induced ALA, to help address this endemic problem on the island of SLK.
\end{abstract}

Keywords: Entamoeba histolytica, Amoebic liver abscess, Sri Lanka, Protozoan

\section{Introduction}

Entamoeba histolytica (E. histolytica) is a non-flagellated, facultative protozoan enteropathogen which affects 50 million individuals globally [1]. It is the fourth leading cause of mortality worldwide due to parasitic infection, and in 2013 was responsible for 11,300 deaths across the globe [2]. In addition to being a significant cause of

\footnotetext{
* Correspondence: tharmegan.tharmaratnam@gmail.com

${ }^{1}$ School of Medicine, Royal College of Surgeons in Ireland, Dublin, Ireland

${ }^{2}$ School of Medicine, Royal College of Surgeons in Ireland-Bahrain, Busaiteen, Bahrain

Full list of author information is available at the end of the article
}

protozoal diarrhea and dysentery, E. histolytica is also the most common cause of amoebic abscesses [3]. This pathogen is endemic to tropical countries, such as Sri Lanka (SLK) and has been a major parasitological health concern on the island since 1962 [4-9]. Overall, the incidence of amoebiasis and ALA have declined significantly in other parts of the island [10] but remains a common cause of emergency department (ED) admission in the north $[6$, 11]. This has been attributed to a multitude of factors such as poor sanitation, hygiene practices, alcohol consumption, male sex, low socioeconomic status (SES), lack of safe water, healthcare facilities and poor access to 
healthcare services $[12,13]$. Opportunities to completely eradicate this pathogen from the island have been circumvented by political unrest and internal displacement, which took place in the northern regions [11, 14]. With the unrest's resolution in 2009, research has once again begun in a concerted effort to eradicate this infection from the island. Thus, preventive medicine is crucial and may contribute to reducing the incidence of illness through the implementation of health policy initiatives and control strategies. This mini-review highlights epidemiological trends, risk factors, diagnostic modalities, treatment approaches, and prevention strategies to reduce transmission and the burden of E. histolytica in SLK.

\section{Epidemiology}

Entamoeba infection can be divided into symptomatic and asymptomatic. Asymptomatic individuals tend to be infected/colonized by mostly non-pathogenic and commensal Entamoeba species, primarily Entamoeba dispar (E. dispar), rather than the pathogenic E. histolytica [1517]. In fact, Herbinger et al. (2011) demonstrated that, in a cohort of 5378 travelers returning back to Germany from elsewhere with symptoms of intestinal infections, PCR had detected E. histolytica and E. dispar in $9.7 \%$ and $88.3 \%$ of cases, respectively; more importantly, however, was the fact that almost all of those with PCR evidence of E. histolytica had symptoms typical of amebiasis, compared with only half with evidence of $E$. dispar [18]. The rest of those with $E$. dispar were determined to be coinfected with other organisms such as Campylobacter spp., Giardia lamblia, and Salmonella typhi. Moreover, some studies have even showed E. dispar colonization in completely asymptomatic HIV-positive individuals, with no evidence of mucosal invasion $[15,19]$.

Up until recently, microscopy has been the most widely used method of diagnosis in studies and in practice [20]. However, microscopy is vastly user-dependent and (unless the user is highly skilled and experienced) lacks ability in diagnosing true amebiasis from amebiasis-like symptoms caused by other microorganisms, but with concomitant E. dispar colonization [21]. As such, going forward with this discussion, it is important that a discrepancy is maintained between the epidemiology of Entamoeba infection (which may be completely asymptomatic) and the epidemiology of the disease itself (amebiasis and its many manifestations, caused primarily by $E$. histolytica).

The World Health Organization (WHO) estimates that around 500 million individuals are infected with Entamoeba spp.; 50 million of those with an invasive disease such as ALA [22]. Other accounts claim that E. histolytica afflicts $10 \%$ of the population worldwide [23], with an estimated death toll of 40,000-100,000 per year, making it the second most common cause of mortality from an infectious parasitic disease [24]. A recent review by Cui et al. (2019) assessing articles that had used molecular methods (PCR) for detection uncovered that, of the 107, 396 total pool of participants of all included studies worldwide, 3817 (3.55\%) were positive for Entamoeba spp.; rates were as low as $0.43 \%$ in Belgium and as high as $82.64 \%$ in Malaysia [22]. It is worth mentioning that, although some studies conducted in developed countries may show high PCR-positivity rates for Entamoeba spp., the proportion of those positive for the virulent $E$. histolytica is minor. For example, out of the 66 patients positive for Entamoeba spp. in a small-scale Canadian study, only $2(0.03 \%)$ were positive for E. histolytica [25]. Similar results are apparent for other studies in other developed countries such as Germany (0.1\%), Sweden (0.06\%), and Australia (0.04\%) $[18,20,26,27]$. In contrast, the proportion of PCRidentified $E$. histolytica infections compared with total Entamoeba infections in developing countries neighboring SLK like India, Bangladesh, Pakistan, and Malaysia were $41.4 \%, 60.2 \%, 17.2 \%$, and $28.1 \%$, respectively [28-43]. Therefore, the literature largely suggests that most infections by E. histolytica occur in developing countries, and those from developed countries that are infected are often returning travelers or immigrants from endemic areas [44]. The burden of disease in developing nations like SLK is primarily due to low SES, inadequate sanitation, and unhygienic practices $[13,45]$. In these areas, symptomatic $E$. histolytica infections are a significant cause of morbidity and mortality, with deaths largely being attributed to complications of infection, such as extra-intestinal manifestations (i.e., ALA) [46].

The first published report of E. histolytica in Sri Lanka dates back to 1962 [7]. Since then, numerous studies have highlighted the burden of this disease as a major public health concern $[6,7,9,11,47]$. In 1985, ALA accounted for $5.9 \%$ of total admissions at the Teaching Hospital Jaffna (THJ) [4]. In 2015, it was reported to be 3.0 per 10,000 admissions at THJ, highlighting that this region of the island is still largely endemic to E. histolytica [6]. In a longitudinal study, Kannathasan et al. reported 346 confirmed ALA cases in northern SLK over a 3-year period, with $99.7 \%$ of serum samples testing positive for the IgG antibody against E. histolytica [48]. While no current data exists on other parts of the island, an early study by Rajasuriya and Nagaratnam (1962) reported $1.5 \%$ of total admissions at the General Hospital Colombo, the capital city, are due to ALA [7]. A more recent report by Kannathasan et al. (2018) states that ALA is seldom seen in other parts of the island compared with northern SLK [6].

\section{Pathogenesis of Entamoeba histolytica}

Relative to other enteropathogens, E. histolytica has a simple life-cycle. Infection begins when humans, the 
solitary natural hosts, ingest quadrinucleated cysts found in fecally contaminated water or food $[45,49]$. It can also occur through swimming in contaminated bodies of water, exposure in endemic areas, and also through person-to-person contact [50, 51]. Once ingested, cysts transit through the gastrointestinal system into the small bowel, and can then migrate to the large intestine. E. histolytica cysts undergo excystation, which releases trophozoites $(10-20 \mu \mathrm{m})$ in the lumen of the intestinal wall, that reproduce via binary fission. The trophozoites then penetrate the colonic mucosa, forming distinct flask-shaped ulcers [50]. The trophozoites can then gain access to the hepatic portal circulation, resulting in hematogenous spread to the liver, which produces an inflammatory reaction leading to necrotic hepatocytes and subsequent abscess formation with a characteristic 'anchovy-paste' exudate [46].

Ultimately, the progression to symptomatic disease is dependent on a multitude of factors including gut microbiome composition, dysbiosis, hosts' age, hosts' genetic composition, immunogenicity (i.e., reduced cellmediated immunity), and the unique interaction between host-immunity and parasitic virulence. These have been shown to be a predictor of disease severity $[9,52-55]$, and are discussed in Fig. 1 below.

\section{Entamoeba histolytica-related virulence factors}

E. histolytica contains several virulence factors, which contribute to its pathogenicity and invasiveness. The most identified virulence factor is the galactose and $\mathrm{N}$ acetyl-d-galactosamine (Gal/GalNAc) specific lectin, which is responsible for the ability of E. histolytica to adhere to mucosal cells in the bowel. This occurs by targeting the $O$-linked polysaccharide side chains of mucin on colonic epithelial cells [54].

While prostaglandin E2 $\left(\mathrm{PGE}_{2}\right)$ functions in impairing macrophage function, it is also known to cause mucus hypersecretion of intraepithelial cells and eventual mucus depletion. Mucus hypersecretion occurs as a host defense mechanism to repel the parasite from adhering to the colonic wall [56]. $\mathrm{PGE}_{2}$ is also known to disrupt tight junction integrity of epithelial cells allowing parasitic infiltration [54, 57], thus increasing gut permeability. This results in chloride secretion into the intestinal lumen, which eventually manifests as amoebic diarrhea [56]. E. histolytica also exerts its pathogenicity through induction of apoptosis of host cells, in addition to a

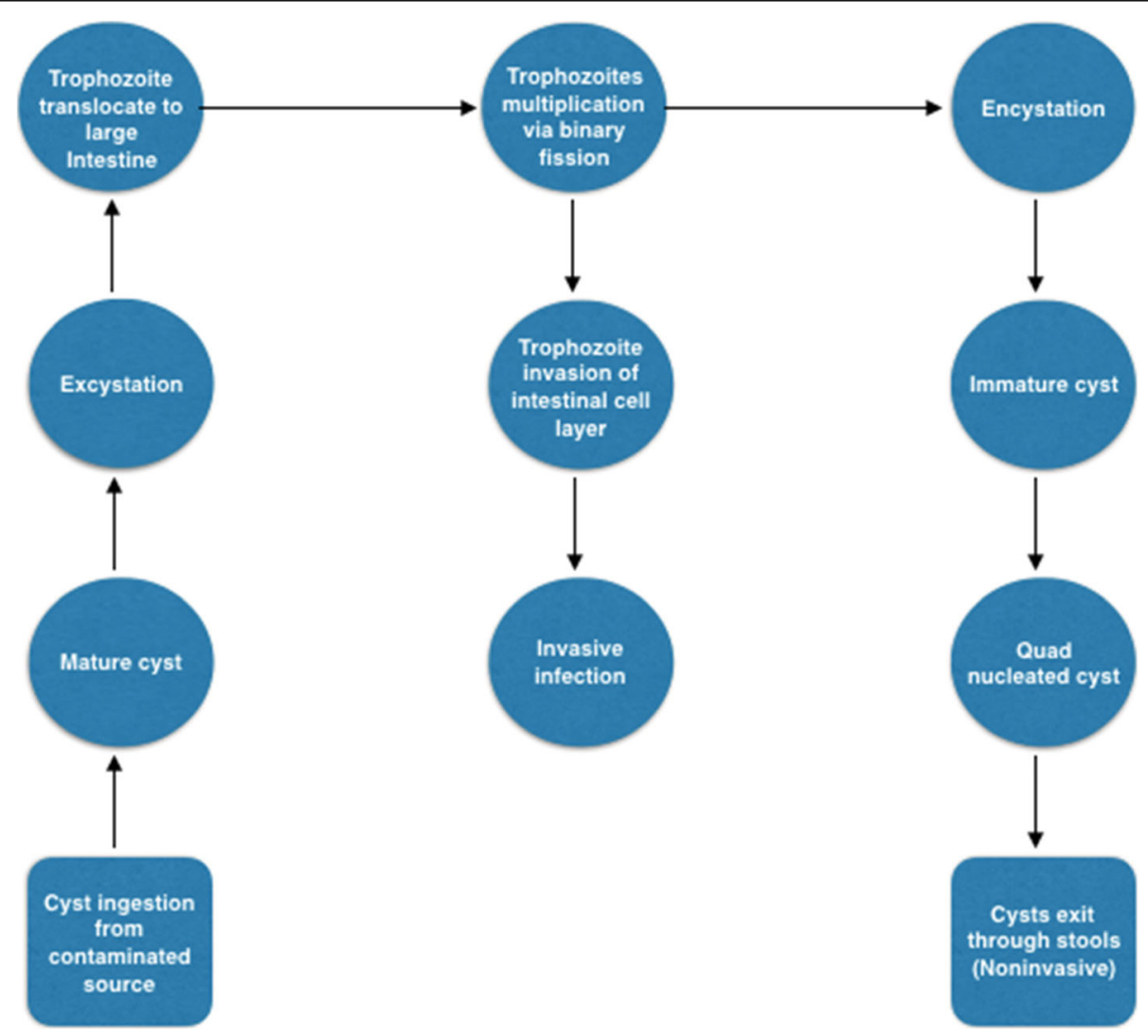

Fig. 1 Schematic representation of the pathogenesis of E. histolytica from ingestion to extra-intestinal hepatic invasion 
relatively new mechanism of cell-destruction called 'trogocytosis' (ingestion of small constituents of host cells, prior to induction of apoptosis) [58, 59].

Another virulence factor contributing to the colonic mucosal barrier breach in E. histolytica trophozoites are cysteine proteases $(\mathrm{CP})$, which are hydrolytic enzymes that participate in the destruction of host epithelial and inflammatory cells and subsequent invasion. In E. histolytica, CP-1, CP-2, and CP-5 account for $90 \%$ of all cysteine protease activities during infection, with CP-5 being the most predominant in degradation of the epithelial mucus layer [56]. CP-5 secretion induces cleavage of C-terminus of the MUC2 protein, which leads to degradation of the protective mucin barrier, and subsequent invasion and increased gut hyperpermeability. Peroxiredoxin, alcohol dehydrogenase, and lipopeptidophosphoglycan are other virulence factors which are implicated in the evasion of host defenses by E. histolytica [60].

Ultimately, invasive diseases of the colonic mucosa require disruptions in the extracellular matrix (ECM) for progression into the lamina propria. E. histolytica produces $E$. histolytica migration inhibitory factor (EhMIF), which causes mucosal inflammation and downstream production of matrix metalloproteinases (MMPs), leading to ECM degradation and invasion [58], thus EhMIF further contributes to disseminated disease. Trophozoites enter the liver hematogenously through the hepatic circulation, forming microabscesses that eventually amalgamate to form a well-circumscribed ALA, generally in the posterior right lobe [61]. The abscess generally consists of inflammatory debris, dead hepatocytes, and amoebic trophozoites surrounded by a rim of connective tissue, with a characteristic "anchovy paste" exudate $[62,63]$.

\section{Risk factors}

Several risk factors are involved in the development of ALA via invasion of E. histolytica into the hepatic circulation. These risk factors are discussed in detail below.

\section{Alcohol consumption}

Indigenous alcohol consumption, particularly from the fermented sap of the Palmyra toddy (Borassus falbellifer) is a well-known cause of ALA in SLK [13], such correlation has previously been demonstrated in several large population-based studies [3, 6, 64]. An early study by Hai et al. (1991) demonstrated that alcohol consumption was implicated in $85 \%$ of 220 confirmed ALA cases [65]. In another study of 50 confirmed ALA cases over a 15month period, Fernando et al. (2011) reported 96\% of ALA cases were attributable to Palmyra toddy consumption [6], a practice widely associated with lower socioeconomic background (i.e., labourers) within taverns where hygienic conditions are often poor [66].
Kannathasan et al. (2014) assessed knowledge and attitudes regarding ALA in a cohort of 90 patients admitted to THJ for ALA. They concluded $80 \%$ to be regular alcohol consumers, with $90 \%$ under the belief that alcohol had no detrimental impact on the liver [67]. In a more recent longitudinal study of 367 ALA patients between 2012 and 2015, Kannathasan et al. (2018) demonstrated alcohol consumption to be an independent risk factor for ALA (OR 4.5; 95\% CI 1.94-11.96) [6]. Additionally, almost all patients were males (largely between 31 and 50 years of age) with a history of alcohol consumption. Interestingly, the highest consumption occurred during the dry season, which correlated to peak alcohol sales in the northern region [7, 10]. Currently, data supports an association between the consumption of indigenous alcoholic beverages and ALA [64,68]. While it is unclear how $E$. histolytica enters the alcoholic beverages prior to consumption to cause disease, theories suggest that it may be due to factors such as water contamination, unhygienic practices in toddy taverns such as open-air defecation, improper hand hygiene, and water filtration practices (cysts are resistant to low doses of chlorination) $[9,69]$.

Numerous mechanisms have been postulated to explain the link between alcohol consumption and the development of ALA. One such explanation is the 'iron hypothesis', whereby iron sequestration in the liver leads to overload, preventing alcohol metabolism via aldehyde dehydrogenase, requiring iron as a co-factor [68]. Others have suggested the role of alcohol-induced hepatocyte injury to result in reduced immunity, and thus increased susceptibility to infection due to damage of Kupffer cells [64]. In vitro studies have demonstrated that the presence of iron promotes the growth of amoeba, while also contributing to its virulence and cytotoxicity [70], which generally becomes elevated with indigenous alcohol consumption. Indeed, the constituents of toddy include alcohol, as well as iron (11.01 $\mathrm{mg}$ of iron/100 g of toddy) $[9,66]$. While it can only be speculated that iron content in the liver is an important factor in the pathogenesis of ALA, the exact mechanisms remain yet to be elucidated [71]. A proposed mechanism involves the role of chronic alcohol consumption as a contributing factor to ALA development. Specifically, alcohol is known to elicit suppression of circulating hepcidin in the liver, ultimately resulting in an increased number of divalent metal transporter-1 in the enterocytes of the duodenum [72]. The role of iron metabolism may partly explain the lower incidence of ALA amongst females. Indeed, Wuerz and colleagues (2012) suggest that iron deficiency anemia and protective hormonal factors in women of reproductive age as potential explanations for the lower observed ALA rates in females [44]. 
Alcohol consumption as a risk factor for E. histolytica is further exacerbated by increased rates of alcohol consumption on the island, which impose a significant economic burden on the healthcare system [10]. The economic cost of alcohol-related health conditions in SLK accounts for $1.07 \%$ of the GDP (885.7 million USD), with direct costs to alcohol-associated conditions estimated to be 388.3 million USD [73]. Importantly, the WHO reports $5.6 \%$ of the population in SLK to have alcoholism, which is greater than the entire Southeast Asia region (3.0\%) [74]. Rates of alcoholism coupled with poor sanitation in toddy taverns and inadequate personal hygiene provide the perfect milieu for E. histolytica to develop. Indeed, Mukhopadhyay et al. (2010) demonstrated patients with alcoholism generally have ALA of greater size, coupled with delayed resolution and greater frequency of complications [3].

\section{Socioeconomic status and poor hygiene}

Poor sanitary conditions coupled with unhygienic practices are common amongst individuals of low SES and provide the optimal environment for the development of ALA in SLK [6, 11, 40]. An early study in neighboring India demonstrated $67.5 \%$ of ALA patients to be of low SES, with $72 \%$ afflicted with high alcohol consumption [64]. A more recent study by Kumanan et al. (2018) demonstrated the majority of ALA cases in SLK arise in from families of lower SES, such as manual laborers and farmers, where good hygiene often cannot be expected [9]. In another study by Kannathasan et al. (2018) from the northern region, $97 \%$ of ALA patients drank toddy, and over $80 \%$ obtained their drinking water from unprotected wells; $88 \%$ drank toddy at taverns; $80 \%$ practiced open-air defecation at the taverns [6].

SES may also be correlated to geographical location. In fact, Kannathasan et al. (2018) demonstrated that 75\% of patients diagnosed with ALA originated from the rural regions of SLK [6]. This may be associated with a lack of infrastructure and healthcare disparities in these regions, which could contribute to the burden of disease. Indeed, Wuerz and colleagues (2012) suggest SES to be a risk factor for invasive amebiasis, including ALA [44].

\section{Male sex}

ALA generally affects men between 18 and 50 years of age, with the greatest prevalence occurring between the 4 th and 5 th decades of life $[18,42]$. The prevalence is also estimated to be 7-10 times greater in males compared with females [52, 53]. Singh et al. (2019) demonstrated that amongst 115 ALA cases in India, 93\% were reported in males. These patients were four times more likely to have a habit of alcohol consumption (OR 4.0; 95\% CI 1.2-13; $p=0.019$ ) [46]. Kannathasan et al. (2018) also demonstrated similar findings amongst a cohort of
ALA patients, in which all were found to male, with a history of heavy alcohol consumption [6].

While the predilection to preferentially affect males than females is not entirely clear, several mechanisms have been postulated. These include increased alcohol consumption leading to elevated hepatocellular damage amongst males compared with females [74], which may predispose them to an increased risk of infection. Animal models have also suggested testosterone to favor the development of ALA. Cervantes-Rebolledo et al. (2009) demonstrated ALA to be absent in $50 \%$ of gonadectomized male hamsters, in comparison to an infection rate of $100 \%$ after intraportal administration of trophozoites in non-gonadectomized controls. Assays also demonstrated scarce inflammatory infiltrate and areas of necrosis in gonadectomized hamsters, with a Th2 and Th3 cytokine profile, while non-gonadectomized samples showed a marked Th1 inflammatory cytokine response, suggesting a downregulation of the inflammatory response in gonadectomized models [75]. Another explanation for male-predominance may be related to the aforementioned 'iron hypothesis'. Other factors that can explain the increased prevalence in males is the fact that males in SLK drink more; indeed, a study by the WHO demonstrated the alcohol consumption rate amongst females to be $6.4 \%$, while it was found to be almost nine times more common amongst males (53.1\%) [76].

\section{Clinical manifestations}

ALA is the most common extraintestinal manifestation of $E$. histolytica [77]. However, $90 \%$ of infected patients remain asymptomatic, while only $10-20 \%$ become symptomatic [49]. The two most common presenting complaints of ALA in symptomatic patients are right hypochondriac pain, and fever $\left(38.5\right.$ to $\left.39.5^{\circ} \mathrm{C}\right)$, which generally presents within $2-4$ weeks in $50-80 \%$ of individuals $[6,13,44,52]$. Patients may also present with nausea, vomiting, weakness, weight loss, and referred pain to the shoulder in some cases. Patients may or may not present with jaundice [78].

Generally, simultaneous colonic infection is seen in 50\% of patients, presenting with ulcers commonly near the ileocecal valve and cecum [13]. Other complications include acute fulminant necrotizing amoebic colitis, toxic megacolon, toxic myocarditis, right iliac fossa mass, and acute appendicitis [47, 79-82]. Recent work also suggests increased co-infection rates of entamoeba with concomitant pulmonary tuberculosis [83], as well as a greater prevalence of rates of infection in patients with inflammatory bowel disease (Crohn's disease or ulcerative colitis), compared with the general population [84].

Another rare complication is cardiac infection due to ALA rupture and spread to the pericardium, which can cause intrapericardial rupture and resultant cardiac tamponade, or slow-onset pericardial effusion. However, this 
generally occurs if the abscess is found in the left lobe of the liver, which is rare, as most cases affect the posterior right lobe [85]. Hematogenous spread to the brain can also occur, resulting in cerebral amoebiasis, but is exceedingly rare [86]. Finally, the risk of recurrent infection, despite adequate treatment has also been previously described in the literature [87].

Additionally, distinguishing ALA from pyogenic liver abscesses (PLA) is crucial due to the differential approach to management in both conditions (see Table 1), despite similar clinical presentation (pyrexia, RUQ pain, hepatomegaly) [48]. While clinical findings alone may be insufficient to distinguish between PLA and ALA [93], certain clinical features can aid in differentiating the two. For example, generally, PLA is polymicrobial (commonly Klebsiella pneumoniae and Escherichia coli) [92], while E. histolytica is the main culprit in ALA. Additionally, PLA affects older male and female patients (generally in the 6th or 7th decade of life) with a history of diabetes or cholelithiasis, while ALA usually afflicts younger males in resource-limited settings [92]. Blood samples in PLA generally show elevated bilirubin with increased left-shift in white blood cells and hypoalbuminemia, while ALA demonstrates no left-shift, but increased bilirubin levels [88-91]. PLA also occurs in non-endemic settings more commonly and has no sex bias. Considering that PLA is the main differential for ALA, distinguishing between them is crucial for effective treatment and resolution of symptoms [44].

\section{Current diagnostic modalities in Sri Lanka}

ALA is a clinical diagnosis in an endemic region such as SLK. It is supported by the typical radiological appearances presented in ultrasonography of the liver, which is an accessible, non-invasive imaging modality available at most state hospitals. Ultrasonography enables the treating clinician to determine the size, site, and type of

Table 1 Differences between ALA and PLA

\begin{tabular}{ll}
\hline Comparing amoebic liver abcess (ALA) and pyogenic liver abscess (PLA) \\
\hline Amoebic liver abscess (ALA) & Pyogenic liver abscess (PLA) \\
\hline - Mainly monomicrobial with E. & - Polymicrobial with Klebsiella \\
histolytica & pneumoniae and Escherichia coli \\
- Affects younger males in & {$[92]$} \\
resource-limited settings [88] & - Affects older male and female \\
- Blood samples display no left- & patients with history of diabetes \\
shift in white blood cells [88-90] & or cholelithiasis \\
- ALA more commonly affects & - Blood samples generally display \\
males than females & elevated bilirubin with increased \\
- Hyperbilirubinemia [91] & left-shift in white blood cells and \\
- Clinical presentation pyrexia, right & hypoalbuminemia [88-90] \\
upper quadrant pain, & PLA also occurs in non-endemic \\
hepatomegaly & settings more commonly and has \\
& no sex bias \\
& - Clinical presentation pyrexia, right \\
& upper quadrant pain, \\
& hepatomegaly \\
\hline
\end{tabular}

abscess present. Typical liver imaging demonstrates a hypoechoic liver mass. With advancements in molecular biology, ELISA kits are being used for immune diagnosis of E. histolytica infection. For study purposes, PCR for amoeba is performed from aspirated pus, is also used to diagnose amoeba; however, the accessibility and cost are significant limiting factors, in utilizing these modalities.

The use of PCR and immunological/molecular profiling for E. histolytica is seldom used in SLK. Indeed, the first published report providing immunological and molecular evidence that $E$. histolytica as a significant cause of liver abscesses in northern Sri Lanka was in 2018 by Kannathasan and colleagues [48]. In this 3-year study, the authors employed nested PCR from DNA of 50 aspirated pus samples based on the serine-rich $E$. histolytica protein (SREHP) coding gene. The E. histolytica DNA sequence was observed in all samples. The authors also employed IgG ELISA using pus and serum samples from 346 patients and reported $99.7 \%$ of samples to be positive for IgG against E. histolytica, which is comparable to earlier studies [94, 95]. An earlier study by Khairnar et al. (2007) utilized nested PCR in 200 samples on various Entamoeba spp., and concluded that it was a more sensitive diagnostic modality in the detection of E. histolytica, Entamoeba moshkovskii (E. moshkovskii), and E. dispar, compared with ELISA [29]. In another study, Dinoop et al. (2016) compared nested-multiplex, Taqman, and SYBR green real-time PCR as diagnostic modalities for ALA. They concluded that Taqman real-time PCR against the 18s rRNA was the most accurate test, demonstrating the highest positivity rate compared with the other two modalities. Dinoop et al. (2016) also demonstrated that real-time PCR can be utilized as a reliable diagnostic modality, compared with other conventional molecular methods [96].

Despite their limited utility in resource-limited settings such as SLK, serological methods such as PCR and ELISA have high specificity and sensitivity. However, a combination of serology with PCR/antigen detection remains the best approach in diagnosis, as this may increase the overall sensitivity and specificity of diagnosis [97]. A recent study by Wong et al. (2017) employed parallel ELISA using crude soluble antigen and excretory-secretory antigen for E. histolytica trophozoite detection in aspirated pus samples. They demonstrated that utilizing both assays improved the overall efficacy of amoebic serology compared with one assay alone [98]. Additionally, in the presence of imaging findings suggestive of ALA, confirmatory testing using serology and antigen detection should be commenced. This could involve stool microscopy or ELISA-based stool antigen detection. However, considering that ALA and E. histolytica-related colitis are unlikely to occur simultaneously, stool microscopy would generally be negative in 
this scenario. Additionally, stool microscopy cannot reasonably distinguish between Entamoeba spp., and thus molecular testing of aspirated pus may be an alternative method [44, 99]. Nonetheless, the utilization of a combination of diagnostic modalities is particularly crucial in endemic settings, as patients may have been exposed to E.histolytica repeatedly, and thus may remain asymptomatic for years after infection [100]. This may confuse the treating clinician due to the inability to distinguish between past and current infection. However, while a shortcoming of serological tests is false positive, based on prior infection in an endemic area, the antibody response to the Gal/GalNAc lectin is not prolonged. In fact, Haque et al. (2000) demonstrated that ALA can be accurately (96\%) diagnosed via antigen detection of the Gal/GalNAc lectin in patients who had not received metronidazole, in addition to being used as a test of cure [101]. Therefore, accurately selecting methods of diagnosis based on prior infectivity can aid in definitive diagnosis and an appropriate management plan [48].

\section{Radiological findings in amoebic liver abscess}

Focal hepatic lesions of the liver have a broad differential diagnosis heavily dependent on the clinical context of the patient. Ultrasonography and computed tomography (CT) are by far the most utilized modalities, typically in that order, owing to availability and relatively low-cost. When combined, they can yield a confirmed diagnosis of ALA in over $90 \%$ of cases; however, triple-phase CT has higher sensitivity $[61,102]$. Generally, radiological findings of liver abscesses typically consist of circumscribed round or ovoid hypoechoic masses which may be commonly solitary or less commonly multifocal. The central or internal contents are typically of slightly higher complexity than simple fluid and it is common to find a peripheral rim or capsule of enhancement on post-contrast computed tomography assessment without internal enhancement.

The trophozoites access the liver from the gastrointestinal tract via the portal vein to initially form microabscesses which progress and coalesce to a single large lesion [103]. ALA typically demonstrate two imaging phases: pre-suppurative and suppurative. On CT, presuppurative consists of heterogeneous, hypodense, and irregularly contoured lesions that are difficult to differentiate from more aggressive lesions such as tumors. This is important when assessing the clinical context and formulating a differential diagnosis [61]. During the suppurative phase, the appearance becomes more classic for abscesses with coalescence, thin or thick peripheral rim of post-contrast enhancement, and a 'target' or 'ring-enhancing' appearance [61].

When distinguishing between differential considerations, a solitary lesion within the right hepatic lobe ranging from 4 to $12 \mathrm{~cm}$ is more typical of ALA (Fig. 2); however, multifocality does not serve to rule out ALA [44]. Moreover, although ultrasonography is a common starting point for imaging in screening for or confirmation of ALA, a negative ultrasound study should be followed up with CT given differences in sensitivity, predominantly due to operator-dependency of ultrasonography [44]. The main differential consideration is for a pyogenic liver abscess given it is more common than ALA in nonendemic settings [104]. On a case-by-case basis, magnetic resonance imaging (MRI) can be considered for further characterization of the lesion or narrowing of the differential diagnosis, although the modality can be cost- and access-prohibitive in typical endemic regions. Classic appearances would be homogeneously low T1 and high T2. MR signal intensity of the lesion(s) with per-lesional increased T2 signal edema in approximately half the lesions [105]. Generally, the combination of imaging, clinical features, and serology allow for diagnosis in almost all cases with aspiration or drainage of an uncomplicated ALA [62] .

\section{Current approaches to management in Sri Lanka}

Current approaches to treatment in SLK include amebicidal tissue-active agents, such as oral metronidazole therapy (500-750 mg three times orally for approximately 7-10 days), which has been shown to be the drug of choice in $85 \%$ of cases in SLK $[5,106]$. This is largely owing to the fact that it is the only amebicidal drug available in the state sector. Other amebicidal agents that can be used to treat ALA include ornidazole, tinidazole, nitazoxanide, and chloroquine [107, 108]. Patients are expected to commence on luminal medications to eradicate intestinal colonization in the cecum, such as paromomycin $(25-30 \mathrm{mg} / \mathrm{kg}$ orally three times daily for 7 days) $[63,109]$. While there is strong evidence demonstrating that monotherapy is often inadequate in invasive disease, it is not standard practice in SLK, due to being in a resource-limited setting [110]. Other treatment approaches such as ultrasonography-guided drainage of ALA remain controversial, with no difference in mortality rates between medical therapy and aspiration of abscesses in uncomplicated ALA [49, 52]. A Cochrane review concluded that in uncomplicated ALA, aspiration combined with metronidazole compared with metronidazole alone as a treatment modality cannot be supported or contraindicated [106]. A more recent study by Chandak et al. (2019) demonstrated both procedures to be equally effective in the treatment of liver abscesses. The decision to aspirate at the discretion of the treating clinician. In practice, large abscesses $(>5 \mathrm{~cm})$, left lobe abscess, and an abscess with a thin rim of liver parenchyma around it (peripheral abscess) should undergo percutaneous needle aspiration (PNA) owing to the risk 


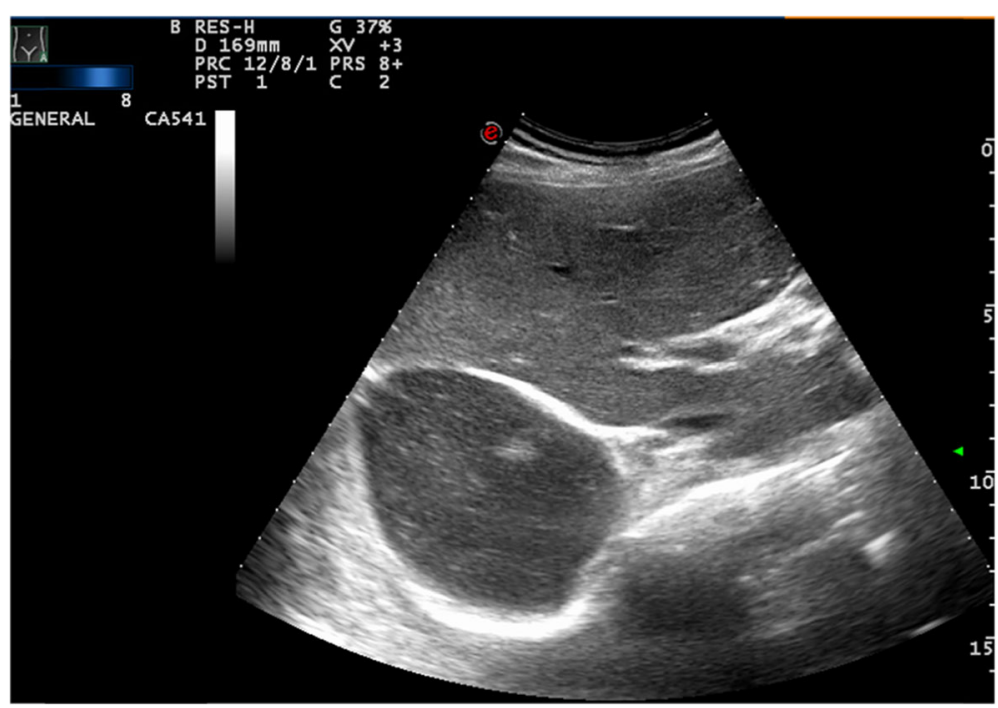

Fig. 2 Ultrasonographic image of ALA in a male patient at Teaching Hospital Jaffna, demonstrating a solitary large right lobe liver abscess

of rupture into the pericardium, pleural cavity, and peritoneum which results in devastating consequences, such as peritonitis and septic shock [44]. The former occurs in approximately $7 \%$ of all cases [111]. In these situations, surgery is necessary and involves a transperitoneal or posterior transpleural approach [112]. Non-resolving pyrexia and persistent symptoms even after $72 \mathrm{~h}$ of initiating tissue amebicides occur indicating poor response to treatment and are also an indication for drainage $[113,114]$. Generally, about $15 \%$ of all cases are refractory to medical therapy, and $20 \%$ of ALA cases may be further exacerbated by superimposed secondary bacterial infection $[115,116]$.

With advances in imaging modalities, minimally invasive ultrasound-guided procedures are utilized, such as ultrasonography-guided percutaneous drainage (Fig. 3), where success rates have been reported to range from $70 \%$ to $100 \%$ [117]. Drainage of the abscess can either be performed with PNA or via pigtail catheter drainage (PCD). The latter has been proven to be a safe technique for both ALA and PLA and has also been shown to result in early relief patients [118]. In comparing these two modalities, pigtail catheter drainage has been shown to be a better option in patients with large abscesses. Despite no differences in mortality, catheter drainage results in faster clinical relief and a shorter duration of parenteral antibiotics $[119,120]$. In an Indian study of 190 patients, of which 95 were treated with PCD, mean hospital stay was shorter, clinical improvement and reduction in cavity size by $50 \%$ were faster in patients treated with PCD compared with PNA. PCD has also been shown to be more effective in the management of PLA, compared with PNA [121]. Indeed, a systematic review of 5 randomized controlled trials of 306 patients reported a 29\% higher success rate with PCD compared with PNA group in patients treated for ALA [relative risk (RR) 0.81, 95\% confidence interval (CI) 0.66-0.99; $p=0.04$ ] [122]. PCD results in more rapid improvement of symptoms as it provides continuous catheterization avoiding re-accumulation of pus and providing more frequent evacuation [117]. However, the main drawbacks of PCD are its higher cost and invasive nature, and a greater likelihood of complications, such as catheter displacement, septicemia, and hemorrhage [123]. Nevertheless, an aforementioned systematic review concluded no significant differences in complications between PCD and PNA [122].

Overall, ALA responds well to treatment with cure rates of $>90 \%$ reported with medical therapy. With appropriate intervention, symptoms typically improve in 3-4 days [124]. Poor prognostic indicators of ALA include hypoalbuminemia (serum albumin $<2.0 \mathrm{~g} / \mathrm{dL}$ ), size and number of abscesses, encephalopathy, and bilirubin levels greater than $3.5 \mathrm{~g} / \mathrm{dL}$, which have all been shown to be independent predictors of mortality [59] .

\section{Barriers to elimination}

Eradication of ALA has been particularly difficult in the northern peninsula of SLK and can be attributed to a multitude of factors. Specifically, over 30 years of prevailed internal political unrest has induced a substantial toll on the healthcare system in the region, as the north and east were the primary conflict zones. The armed conflict adversely affected the projected public health trajectory, resulting in overall worse health outcomes post-war [125], and despite post-conflict healthcare system reconstruction being underway, unmet needs remain. These include water and sanitation systems, 


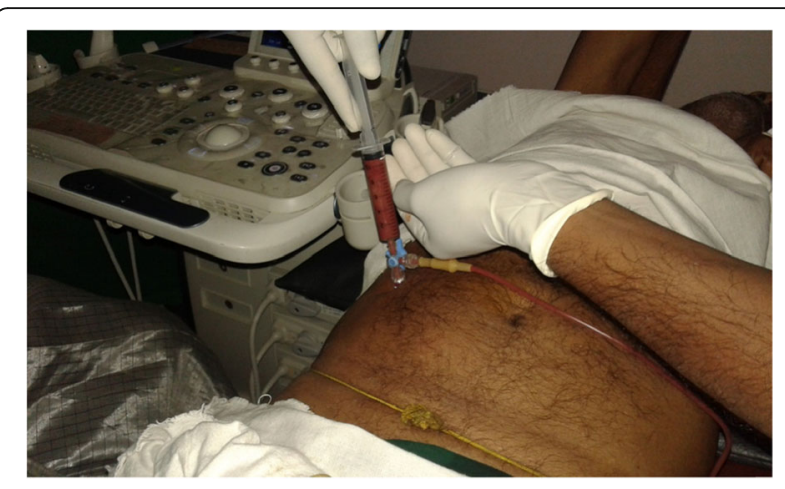

Fig. 3 Therapeutic ultrasonographic-guided percutaneous aspiration of ALA in the right-upper quadrant at $\mathrm{THJ}$ —a relatively safe bedside procedure

access to healthcare facilities, general health awareness programs, lack of basic health knowledge, human resources for health, and inadequate infrastructure. Nagai and colleagues (2007) identified the aforementioned disparities from self-administered questionnaires to healthcare providers and inhabitants of the northern region [126]. As an example, despite the fact that E. histolytica transmission can be reduced markedly with the provision of safe drinking water and sanitation, safe drinking water and adequate latrine facilities deteriorated during the armed conflict and have not completely recovered [126]. In fact, the development of adequate latrine facilities in the north has lagged behind 20 years compared with national averages [126]. Thus, the primary barrier to eradication continues to be poor sanitation and hygiene in the northern region, which has been slow in development compared with other parts of the island post-conflict.

The persistence of ALA in the northern peninsula despite reduced prevalence rates in other parts of the island has been deemed a public health failure [11]. Therefore, empowering residents through implementing health awareness programs (education about harms of regular alcohol consumption [and in particular, the indigenously brewed beverages], mass media campaigns) and improving infrastructure (improving access to healthcare facilities, adequate latrine facilities, improving conditions at toddy taverns) are all crucial to formulate effective elimination strategies for E. histolytica-related ALA infections.

\section{Prevention and future directions}

At present, no vaccine exists to prevent $E$. histolytica-induced ALA. Thus, primary preventive efforts should emphasize the importance of improving sanitation, the provision of safe drinking water, and public health campaigns to promote hygienic practices (i.e., hand-washing, provision of adequate supplies, improving latrine facilities, promoting safe consumption of alcoholic beverages as harm reduction) and food safety [12, 127]. One example is the 'five keys to safer food' (i.e., utilization of clean water and utensils when cooking, separation of raw and cooked foods, ensuring foods are kept at the appropriate temperature and are cooked thoroughly) [128]. Increasing drinking-water hygiene standards in areas endemic to $E$. histolytica is recommended. The WHO Guidelines for Drinking-Water Quality shows that E. histolytica has a high resistance to traditional low-dose chlorination practices and transmission of $E$. histolytica through potable water sources is common in the tropical regions [129]. The WHO's guidelines recommend that drinking water be prevented from contamination by human waste and that adequate protection is provided during the transportation of potable water supplies. The boiling of drinking water for $1 \mathrm{~min}$ or the addition of iodine to drinking water supplies is highly recommended to sanitize water sources of E. histolytica cysts prior to human consumption. Water Safety Plans (WSPs) are a WHO framework that provide a risk management strategy for drinking water supplies and provide a systematic approach to ensure that the safety and quality of the drinking water meets WHO standards. WSPs are covered in WHO's Guidelines for Drinking-Water Quality and if utilized properly, will provide the policies and framework necessary to implement the WHO recommendations to ensure quality drinking water [129].

Another preventive strategy can be employed amongst child-rearing women. Expectant mothers and those with infants should be taught the importance of breastfeeding (i.e., breastfeed exclusively for the first 6 months of life and up to 2 years and beyond), as it is an effective way to protect them from acquiring diarrheal disease [12]. This is important as E. histolytica has been listed as one of the top-15 causes of diarrhea in the first 2 years of life [2, 127].

Educating patients about the harms of regular alcohol consumption is also warranted. There appears to be a lack of understanding amongst the population about regular consumption of alcohol and liver damage [67]. Additionally, there is also a general lack of knowledge amongst patients about ALA, the causative agent, risk factors, and the adoption of preventive measures [6]. The World Health Assembly's adopted resolution EB126.R11, a global strategy to reduce the harmful use of alcohol, has undergone new adaptations, including expanding the evidence base such that it applies to low- and middle-income countries. In addition to this, the WHO has adopted scientific support for the interventions in its new global strategy, including to increase the capacity of health and social welfare systems to deliver treatment and early intervention, limits on alcohol availability, restrictions on alcohol marketing, and pricing policies to discourage alcohol consumption [130]. 
Strategies to increase awareness such as mass media campaigns and community-level interventions are necessary, particularly to those who are at risk, in order to eradicate the disease from the island. These could include education about safe limits of alcohol consumption, as frequency and type of alcohol consumed have been shown to be risk factors for ALA [6], as well as education on safe brewing practices of indigenous beverages as a harm reduction strategy.

\section{Conclusion}

E. histolytica is a public health problem in northern SLK, owing to poor sanitation and poor hygienic practices, particularly in the production of indigenous alchoholic beverages. Middle-aged men with a history of alcohol consumption are particularly at high risk, which is exacerbated by the lack of knowledge and attitudes about ALA, its route of transmission, and general neglect towards practicing good hygiene in toddy taverns. As a preventable illness, this imposes a significant burden on the healthcare system and substantial opportunity for improvement still exists to address this healthcare disparity.

\begin{abstract}
Abbreviations
ALA: Amoebic liver abscess; CP: Cysteine proteases; CT: Computed tomography; E. dispar: Entamoeba dispar; E. histolytica: Entamoeba histolytica; E. moshkovskii: Entamoeba moshkovskii; ELISA: Enzyme-linked immunosorbent assay; Gal/GalNAc: Galactose and N-acetyl-d-galactosamine;

IBD: Inflammatory bowel disease; PCD: Pigtail catheter drainage;

PCR: Polymerase chain reaction; PLA: Pyogenic liver abscess;

PNA: Percutaneous needle aspiration; rRNA: Ribosomal ribonucleic acid;

SES: Socioeconomic status; SLK: Sri Lanka; THJ: Teaching Hospital Jaffna;

WHO: World Health Organization; WSPs: Water Safety Plans
\end{abstract}

\section{Acknowledgements}

None.

\section{Authors' contributions}

$\Pi T$ initiated and carried out the literature search for this mini-review, as well as analysis and interpretation of the data and manuscript drafting. TK drafted the 'Current approaches to management in Sri Lanka' section. KD, SS TT, and ML provided guidance in the drafting of this manuscript, as well as a critical review of drafts for important intellectual content. MAI drafted the epidemiology section, was involved in review of the manuscript, referencing, and the risk factors section. PGR drafted the 'radiological findings in amoebic liver abscess section' and was involved in interpretation of the data. TAT drafted the prevention and future directions section. IT provided administrative support and review of the final draft for important intellectual content. All authors have read and approve the final version of this manuscript.

\footnotetext{
Authors' information

Tharmegan Tharmaratnam's initial conception of this manuscript idea was inspired by the preponderance of E.histolytica-related ALA admissions at the Teaching Hospital Jaffna, during a 3rd world medical elective in December 2018 in the Internal Medicine Unit, Faculty of Medicine, University of Jaffna. His preceptor during that time was Dr. Thirunavukarasu Kumanan, an honorary consultant physician at Teaching Hospital Jaffna.
}

\section{Funding}

This study was supported by the RCSI-MUB Postgraduate Research Fund which covered the open-access publishing fee of this article.
Availability of data and materials

Not applicable.

Ethics approval and consent to participate

Not applicable.

\section{Consent for publication}

Consent for publication was obtained for Fig. 2 from the patient.

\section{Competing interests}

The authors declare that they have no competing interests.

\section{Author details}

${ }^{1}$ School of Medicine, Royal College of Surgeons in Ireland, Dublin, Ireland. ${ }^{2}$ School of Medicine, Royal College of Surgeons in Ireland-Bahrain, Busaiteen, Bahrain. ${ }^{3}$ Department of Internal Medicine, Faculty of Medicine, University of Jaffna, Jaffna, Sri Lanka. ${ }^{4}$ Teaching Hospital Jaffna, Faculty of Medicine, University of Jaffna, Jaffna, Sri Lanka. ${ }^{5}$ Department of Diagnostic Radiology, Hamilton Health Sciences Centre, Hamilton, ON, Canada. ${ }^{6}$ Department of Radiology, Michael G. DeGroote School of Medicine, McMaster University, Hamilton, ON, Canada. ${ }^{7}$ Academic Family Health Team, Mount Sinai Hospital, Faculty of Medicine, University of Toronto, Toronto, ON, Canada.

${ }^{8}$ Department of Family and Community Medicine, Faculty of Medicine, University of Toronto, Toronto, ON, Canada. ${ }^{9}$ Department of Family Medicine, Brantford General Hospital, Hamilton, ON, Canada. ${ }^{10}$ Department of Family Medicine, Michael G. DeGroote School of Medicine, McMaster University, Hamilton, ON, Canada. ${ }^{11}$ Department of Physical and Environmental Sciences, University of Toronto, Toronto, ON, Canada. ${ }^{12}$ Stonechurch Family Health Clinic, Department of Family Medicine, Michael G. DeGroote School of Medicine, McMaster University, Hamilton, ON, Canada. ${ }^{13}$ Department of Pathology and Clinical Microbiology, School of Medicine, Royal College of Surgeons in Ireland-Bahrain, Busaiteen, Bahrain.

Received: 22 October 2019 Accepted: 16 January 2020

Published online: 22 January 2020

\section{References}

1. World Health Organization (WHO). Pan American health organization. UNESCO report of a consultation of experts on amoebiasis. Wkly Epidemiol Rec. 1997;72:97-9.

2. Wang H, Naghavi M, Allen C, Barber RM, Bhutta ZA, Carter A, et al. Global, regional, and national life expectancy, all-cause mortality, and cause-specific mortality for 249 causes of death, 1980-2015: a systematic analysis for the global burden of disease study 2015. Lancet. 2016:388(10053):1459-544.

3. Mukhopadhyay M, Saha AK, Sarkar A, Mukherjee S. Amoebic liver abscess: presentation and complications. Indian J Surg. 2010;72(1):37-41.

4. Sreeharan N, Yogeswaran P, Puthrasingam S, Ranjadayalan K, Ganeshamoorthy J. Hepatic amoebiasis in northern Sri Lanka: a retrospective study. Jaffna Med J. 1985;20(2):69-74.

5. Fernando K, Fernando R, Kandasami A, Jude R, Fernando N, Tennakoon S. SP6-3 Fermented sap of spiky Palmyra toddy (Borassus flabellifer) suggested as a vehicle of transportation of amoebiasis in the district of Mannar, Sri Lanka: 50 cases of amoebic liver abscess within 15 months. J Epidemiol Community Health. 2011;65(Suppl 1):A455-A.

6. Kannathasan S, Murugananthan A, Kumanan T, de Silva NR, Rajeshkannan N, Haque R, et al. Epidemiology and factors associated with amoebic liver abscess in northern Sri Lanka. BMC Public Health. 2018;18(1):118.

7. Rajasuriya K, Nagaratnam N. Hepatic amoebiasis in Ceylon. J Trop Med Hyg. 1962:65(7):165-78

8. Taha HA. Intestinal parasitic infections among expatriate workers in AlMadina Al-munawarah, kingdom of Saudi Arabia. Trop Biomed. 2013; 30(1):78-88.

9. Kumanan T, Sujanitha V, Balakumar S, Sreeharan N. Amoebic liver abscess and indigenous alcoholic beverages in the tropics. J Trop Med. 2018;2018.

10. De Silva N, De Silva H, Jayapani V. Intestinal parasitoses in the Kandy area, Sri Lanka. Southeast Asian J Trop Med Public Health. 1994:25:469.

11. Kannathasan S, De Silva N, Kumanan T. Persistence of amoebiasis in northern Sri Lanka-a public health failure. J Ceylon College Physicians. 2017; 48(2):88-9.

12. World Health Organization. Communicable disease epidemiological profile: Sri Lanka. Geneva: World Health Organization; 2010. Available from: https:// 
apps.who.int/iris/bitstream/handle/10665/70514/WHO_HSE_GAR_DCE_2010. 7_eng.pdf? sequence=1\&isAllowed=y. Accessed 25 Nov 2019

13. Bhatia SJ, Sundaram S. Amoebic liver abscess with synchronous colitis: lessons learnt in recent times. J Assoc Physicians India. 2019;67:11.

14. Siriwardhana C, Wickramage K. Conflict, forced displacement and health in Sri Lanka: a review of the research landscape. Confl Heal. 2014;8(1):22.

15. Burch DJ, Li E, Reed S, Jackson T, Stanley S. Isolation of a strain-specific Entamoeba histolytica cDNA clone. J Clin Microbiol. 1991;29(4):696-701.

16. Clark CG, Diamond LS. Ribosomal RNA genes of 'pathogenic'and 'nonpathogenic' Entamoeba histolytica are distinct. Mol Biochem Parasitol. 1991:49(2):297-302.

17. Tannich E, Horstmann RD, Knobloch J, Arnold HH. Genomic DNA differences between pathogenic and nonpathogenic Entamoeba histolytica. Proc Natl Acad Sci. 1989;86(13):5118-22.

18. Herbinger KH, Fleischmann E, Weber C, Perona P, Löscher T, Bretzel G. Epidemiological, clinical, and diagnostic data on intestinal infections with Entamoeba histolytica and Entamoeba dispar among returning travelers. Infection. 2011;39(6):527-35.

19. Allason-Jones E, Mindel A, Sargeaunt P, Williams P. Entamoeba histolytica as a commensal intestinal parasite in homosexual men. N Engl J Med. 1986; 315(6):353-6.

20. Fotedar R, Stark D, Beebe N, Marriott D, Ellis J, Harkness J. Laboratory diagnostic techniques for Entamoeba species. Clin Microbiol Rev. 2007;20(3): 511-32.

21. Turkeltaub JA, McCarty TR III, Hotez PJ. The intestinal protozoa: emerging impact on global health and development. Curr Opin Gastroenterol. 2015; 31(1):38-44

22. Cui Z, Li J, Chen Y, Zhang L. Molecular epidemiology, evolution, and phylogeny of Entamoeba spp. Infect Genet Evol. 2019;104018.

23. Begum S, Quach J, Chadee K. Immune evasion mechanisms of Entamoeba histolytica: progression to disease. Front Microbiol. 2015;6:1394.

24. Walsh J. Prevalence of Entamoeba histolytica infection. Human Infection by Entamoeba histolytica. 1988:93-105

25. Gonin P, Trudel L. Detection and differentiation of Entamoeba histolytica and Entamoeba dispar isolates in clinical samples by PCR and enzymelinked immunosorbent assay. J Clin Microbiol. 2003;41(1):237-41.

26. Lebbad M, Svärd SG. PCR differentiation of Entamoeba histolytica and Entamoeba dispar from patients with amoeba infection initially diagnosed by microscopy. Scand J Infect Dis. 2005;37(9):680-5

27. Stark D, van Hal SJ, Matthews G, Harkness J, Marriott D. Invasive amebiasis in men who have sex with men, Australia. Emerg Infect Dis. 2008;14(7):1141.

28. Khairnar K. Parija SC. Detection of Entamoeba histolytica DNA in the saliva of amoebic liver abscess patients who received prior treatment with metronidazole. J Health Popul Nutr. 2008;26(4):418.

29. Khairnar K, Parija SC, Palaniappan R. Diagnosis of intestinal amoebiasis by using nested polymerase chain reaction-restriction fragment length polymorphism assay. J Gastroenterol. 2007;42(8):631-40.

30. Parija SC, Khairnar K. Mutation detection analysis of a region of 16S-like ribosomal RNA gene of Entamoeba histolytica, Entamoeba dispar and Entamoeba moshkovskii. BMC Infect Dis. 2008;8(1):131.

31. Mukherjee AK, Chowdhury P, Bhattacharya MK, Ghosh M, Rajendran K Ganguly S. Hospital-based surveillance of enteric parasites in Kolkata. BMC Res Notes. 2009:2(1):110.

32. Nath J, Banyal N, Gautam D, Ghosh S, Singha B, Paul J. Systematic detection and association of Entamoeba species in stool samples from selected sites in India. Epidemiol Infect. 2015;143(1):108-19.

33. Nath J, Ghosh SK, Singha B, Paul J. Molecular epidemiology of amoebiasis: a cross-sectional study among north east Indian population. PLoS Negl Trop Dis. 2015;9(12):e0004225.

34. Nath J, Hussain G, Singha B, Paul J, Ghosh SK. Burden of major diarrheagenic protozoan parasitic co-infection among amoebic dysentery cases from north East India: a case report. Parasitology. 2015;142(10):1318-25.

35. Ali IKM, Hossain MB, Roy $S$, Ayeh-Kumi PF, Petri WA Jr, Haque R, et al. Entamoeba moshkovskii infections in children in Bangladesh. Emerg Infect Dis. 2003;9(5):580.

36. Petri WA Jr, Haque R, Mondal D, Karim A, Molla IH, Rahim A, et al. Prospective case-control study of the association between common enteric protozoal parasites and diarrhea in Bangladesh. Clin Infect Dis. 2009;48(9): $1191-7$.

37. Royer TL, Gilchrist C, Kabir M, Arju T, Ralston KS, Haque R, et al. Entamoeba bangladeshi nov. sp., Bangladesh. Emerg Infect Dis. 2012;18(9):1543.
38. Yakoob J, Abbas Z, Beg MA, Naz S, Khan R, Jafri W. Entamoeba species associated with chronic diarrhoea in Pakistan. Epidemiol Infect. 2012;140(2):323-8.

39. Noor Azian M, Lokman Hakim S, Maslawaty M. Use of molecular tools to distinguish Entamoeba histolytica and Entamoeba dispar infection among the aborigines in Cameron Highlands. Trop Biomed. 2006;23(1):31-6.

40. Anuar TS, Al-Mekhlafi HM, Ghani MKA, Azreen SN, Salleh FM, Ghazali N, et al. First molecular identification of Entamoeba moshkovskii in Malaysia. Parasitology. 2012;139(12):1521-5.

41. Anuar TS, Al-Mekhlafi HM, Ghani MKA, Bakar EA, Azreen SN, Salleh FM, et al. Molecular epidemiology of amoebiasis in Malaysia: highlighting the different risk actors of Entamoeba histolytica and Entamoeba dispar infections among orang Asli communities. Int J Parasitol. 2012;42(13-14):1165-75.

42. Basuni M, Mohamed Z, Ahmad M, Zakaria N, Noordin R. Detection of selected intestinal helminths and protozoa at Hospital Universiti Sains Malaysia using multiplex real-time PCR. Trop Biomed. 2012;29(3):434-42.

43. Ngui $R$, Angal L, Fakhrurrazi SA, Lian YLA, Ling LY, Ibrahim J, et al. Differentiating Entamoeba histolytica, Entamoeba dispar and Entamoeba moshkovskii using nested polymerase chain reaction (PCR) in rural communities in Malaysia. Parasit Vectors. 2012;5(1):187.

44. Wuerz T, Kane JB, Boggild AK, Krajden S, Keystone JS, Fuksa M, et al. A review of amoebic liver abscess for clinicians in a nonendemic setting. Can J Gastroenterol Hepatol. 2012;26(10):729-33.

45. Kantor M, Abrantes A, Estevez A, Schiller A, Torrent J, Gascon J, et al. Entamoeba Histolytica: updates in clinical manifestation, pathogenesis, and vaccine development. Can J Gastroenterol Hepatol. 2018;2018:4601420.

46. Singh A, Banerjee T, Kumar R, Shukla SK. Prevalence of cases of amebic liver abscess in a tertiary care Centre in India: a study on risk factors, associated microflora and strain variation of Entamoeba histolytica. PLoS One. 2019; 14(4):e0214880

47. Ratnasamy V, Thirunavukarasu K, Selvam K, Arumugam M. Amoebic liver abscess: an unusual cause for a right iliac fossa mass: a case report. BMC Infect Dis. 2016;16(1):741.

48. Kannathasan S, Murugananthan A, Kumanan T, Iddawala D, de Silva NR, Rajeshkannan $\mathrm{N}$, et al. Amoebic liver abscess in northern Sri Lanka: first report of immunological and molecular confirmation of aetiology. Parasit Vectors. 2017:10(1):14.

49. Stanley SL Jr. Amoebiasis. Lancet. 2003;361 (9362):1025-34.

50. Ralston KS, Petri WA Jr. Tissue destruction and invasion by Entamoeba histolytica. Trends Parasitol. 2011;27(6):254-63.

51. Taherian M, Samankan S, Cagir B. Amebic colitis. StatPearls. Treasure Island (FL): StatPearls Publishing. StatPearls Publishing LLC.; 2019.

52. Haque R, Huston CD, Hughes M, Houpt E, Petri WA Jr. Amebiasis. N Engl J Med. 2003;348(16):1565-73.

53. Bernin $\mathrm{H}$, Marggraff $\mathrm{C}$, Jacobs T, Brattig N, Blessmann J, Lotter H. Immune markers characteristic for asymptomatically infected and diseased Entamoeba histolytica individuals and their relation to sex. BMC Infect Dis. 2014;14(1):621.

54. Nakada-Tsukui K, Nozaki T. Immune response of amebiasis and immune evasion by Entamoeba histolytica. Front Immunol. 2016;7:175.

55. Shahi P, Moreau F, Chadee K. Entamoeba histolytica cyclooxygenase-like protein regulates cysteine protease expression and virulence. Front Cell Infect Microbiol. 2018;8:447.

56. Cornick S, Chadee K. Entamoeba histolytica: host parasite interactions at the colonic epithelium. Tissue Barriers. 2017;5(1):e1283386.

57. Lejeune M, Moreau F, Chadee K. Prostaglandin E2 produced by Entamoeba histolytica signals via EP4 receptor and alters claudin-4 to increase ion permeability of tight junctions. Am J Pathol. 2011;179(2):807-18.

58. Ghosh S, Padalia J, Moonah S. Tissue destruction caused by Entamoeba histolytica parasite: cell death, inflammation, invasion, and the gut microbiome. Curr Clin Microbiol Rep. 2019;6(1):51-7.

59. Ralston KS, Solga MD, Mackey-Lawrence NM, Bhattacharya A, Petri WA Jr. Trogocytosis by Entamoeba histolytica contributes to cell killing and tissue invasion. Nature. 2014;508(7497):526.

60. Quach J, St-Pierre J, Chadee K The future for vaccine development against Entamoeba histolytica. Hum Vaccines Immunotherapeutics. 2014;10(6):1514-21.

61. Lardière-Deguelte S, Ragot E, Amroun K, Piardi T, Dokmak S, Bruno O, et al. Hepatic abscess: diagnosis and management. J Visceral Surg. 2015;152(4):231-43.

62. Mohidin B, Green S, Duggineni S. Amoebic liver abscess. OJM: An International Journal of Medicine. 2018.

63. Wang HH, Lin WR. Amebic Liver Abscess. New England J Med. 2018;379(23): 2255. 
64. Ghosh S, Sharma S, Gadpayle AK, Gupta H, Mahajan R, Sahoo R, et al. Clinical, laboratory, and management profile in patients of liver abscess from northern India. J Trop Med. 2014;2014.

65. Hai A, Singh A, Mittal V, Karan G. Amoebic liver abscess. Review of 220 cases. Int Surg. 1991;76(2):81-3.

66. Kumar R, Priyadarshi R, Anand U. Toddy consumption and amoebic liver abscess in India: an unexplored link. Indian J Public Health. 2019;63(1):89-90.

67. Kannathasan S, Iddawala W, De Silva N, Haque R. Knowledge, Attitude and Practice Towards Liver Abscess, Among Patients Admitted to the Teaching Hospital, Jaffna; 2014.

68. Kumar R, Jha AK. Association between local alcoholic beverages and amoebic liver abscess in the Indian subcontinent: weird but true! JGH open; 2019.

69. Singh R, Adhikari DR, Patil BP, Talathi NR, Hanamshetti SR, Joshi RM. Amoebic liver abscess: an appraisal. Int Surg. 2011;96(4):305-9.

70. Priti R. Insight and control of infectious disease in global scenario: BoDbooks on demand; 2012

71. Makkar RP, Sachdev GK, Malhotra V. Alcohol consumption, hepatic iron load and the risk of amoebic liver abscess: a case-control study. Intern Med. 2003:42(8):644-9.

72. Cylwik B, Chrostek L, Szmitkowski M. The effect of alcohol on the regulation of iron metabolism. Pol Merkur Lekarski. 2008;25(147):273-5.

73. Ranaweera S, Amarasinghe H, Chandraratne N, Thavorncharoensap M, Ranasinghe T, Karunaratna S, et al. Economic costs of alcohol use in Sri Lanka. PLoS One. 2018;13(6):e0198640.

74. World Health Organization (WHO). Global status report on alcohol and health 2018: World Health Organization; 2019.

75. Cervantes-Rebolleda C, Moreno-Mendoza N, Morales-Montor J, De La Torre P, Laclette J, Carrero J. Gonadectomy inhibits development of experimental amoebic liver abscess in hamsters through downregulation of the inflammatory immune response. Parasite Immunol. 2009;31(8):447-56.

76. Obot IS, Room R. Alcohol, gender and drinking problems: perspectives from low and middle income countries: World Health Organization; 2005

77. Marenga G, Traficante S, Ragonici S, Vincenzi C, Rocchetti M, De Rito G, et al. Successful diagnosis of a longstanding Giant amoebic liver abscess using contrast-enhanced ultrasonography (CEUS): a case report in a Western country. Am J Case Rep. 2019;20:493.

78. Bansal A, Bansal AK, Bansal V, Kumar A. Liver abscess: catheter drainage v/s needle aspiration. Int Surg J. 2016;2(1):20-5.

79. Pathirage LMM, Kularatne SA, Wijesinghe S, Ratnatunga NV, Gawarammana IB. Fulminant colitis and toxic myocarditis: a unifying cause? Lancet. 2009; 374(9706):2026.

80. Raviraj S, Sivashankar M, Ekanayake A. A rare and potentially fatal complication of amoebiasis: acute fulminant necrotizing amoebic colitis. Ceylon Medical Journal. 2017;62(1).

81. Herrera CG, Herrera CA, Pontón P, Molina GA, Constante JE, Delgado JA. Amebiasis, a rare cause of acute appendicitis. J Surg Case Rep. 2019;2019(3):rjz076.

82. Choudhuri G, Rangan M. Amebic infection in humans. Indian J Gastroenterol. 2012;31(4):153-62.

83. Alemu A, Kebede A, Dagne B, Amare M, Diriba G, Yenew B, et al. Intestinal parasites co-infection and associated factors among active pulmonary tuberculosis patients in selected health centers, Addis Ababa, Ethiopia: unmatched case control study. BMC Infect Dis. 2019; 19(1):407.

84. Babić E, Bevanda M, Mimica M, Karin M, Volarić M, Bogut A, et al. Prevalence of amebiasis in inflammatory bowel disease in university clinical hospital Mostar. Springer Plus. 2016;5(1):1586.

85. Miyauchi T, Takiya H, Sawamura T, Murakami E. Cardiac tamponade due to intrapericardial rupture of an amebic liver abscess. Jpn J Thorac Cardiovasc Surg. 2005;53(4):206-9.

86. Maldonado-Barrera CA, del Rosario C-EM, Muñoz-Fernández L, VictoriaHernández JA, Campos-Rodríguez R, Talamás-Rohana P, et al. Clinical case of cerebral amebiasis caused by E. histolytica. Parasitol Res. 2012;110(3):1291-6.

87. Creemers-Schild D, van Genderen P, Visser L, van Hellemond J, Wismans $P$. Recurrent amebic liver abscesses over a 16-year period: a case report. BMC research notes. 2016;9(1):472.

88. Bhatti AB, Ali F, Satti SA, Satti TM. Clinical and pathological comparison of pyogenic and amoebic liver abscesses. Adv Infect Dis. 2014;4(03):117.

89. Cosme A, Ojeda E, Zamarreño I, Bujanda L, Garmendia G, Echeverría M, et al. Pyogenic versus amoebic liver abscesses. A comparative clinical study in a series of 58 patients. Revista Espanola de Enfermedades Digestivas. 2010;102(2):90.
90. Abbas MT, Khan FY, Muhsin SA, Al-Dehwe B, Abukamar M, Elzouki A-N. Epidemiology, clinical features and outcome of liver abscess: a single reference center experience in Qatar. Oman Med J. 2014;29(4):260.

91. Sharma M, Dasarathy S, Verma N, Saksena S, Shukla DK. Prognostic markers in amebic liver abscess: a prospective study. American Journal of Gastroenterology. 1996;91(12).

92. Johannsen EC, Sifri CD, Madoff LC. Pyogenic liver abscesses. Infect Dis Clin N Am. 2000;14(3):547-63.

93. Ahsan T, Jehangir M, Mahmood T, Ahmed N, Saleem M, Shahid M, et al. Amoebic versus pyogenic liver abscess. J Pak Med Assoc. 2002;52(11):497-501.

94. Kraoul L, Adjmi H, Lavarde V, Pays J, Tourte-Schaefer C, Hennequin C. Evaluation of a rapid enzyme immunoassay for diagnosis of hepatic amoebiasis. J Clin Microbiol. 1997;35(6):1530-2.

95. Mathur S, Gehlot R, Mohta A, Bhargava N. Clinical profile of amoebic liver abscess. J Indian Acad Clin Med. 2002:3:367-73.

96. Dinoop K, Parija SC, Mandal J, Swaminathan R, Narayanan P. Comparison of nested-multiplex, Taqman \& SYBR Green real-time PCR in diagnosis of amoebic liver abscess in a tertiary health care institute in India. Indian J Med Res. 2016;143(1):49.

97. Cheepsattayakorn A, Cheepsattayakorn R. Parasitic pneumonia and lung involvement. Biomed Res Int. 2014:2014.

98. Wong WK, Foo PC, Olivos-Garcia A, Noordin R, Mohamed Z, Othman N, et al. Parallel ELISAs using crude soluble antigen and excretory-secretory antigen for improved serodiagnosis of amoebic liver abscess. Acta Trop. 2017;172:208-12.

99. Pritt BS, Clark CG, editors. Amebiasis. Mayo Clinic Proceedings; 2008: Elsevier.

100. Haque R, Kabir M, Noor Z, Rahman SM, Mondal D, Alam F, et al. Diagnosis of amebic liver abscess and amebic colitis by detection of Entamoeba histolytica DNA in blood, urine, and saliva by a real-time PCR assay. J Clin Microbiol. 2010;48(8):2798-801.

101. Haque R, Mollah NU, Ali IK, Alam K, Eubanks A, Lyerly D, et al. Diagnosis of amebic liver abscess and intestinal infection with the TechLab Entamoeba histolytica II antigen detection and antibody tests. J Clin Microbiol. 2000; 38(9):3235-9.

102. Halvorsen R, Korobkin M, Foster W, Silverman P, Thompson W. The variable CT appearance of hepatic abscesses. Am J Roentgenol. 1984;142(5):941-6.

103. Espinosa-Cantellano M, Martínez-Palomo A. Pathogenesis of intestinal amebiasis: from molecules to disease. Clin Microbiol Rev. 2000;13(2):318-31.

104. Lederman ER, Crum NF. Pyogenic liver abscess with a focus on Klebsiella pneumoniae as a primary pathogen: an emerging disease with unique clinical characteristics. Am J Gastroenterol. 2005;100(2):322.

105. Mortelé KJ, Segatto E, Ros PR. The infected liver: radiologic-pathologic correlation. Radiographics. 2004;24(4):937-55.

106. Chavez-Tapia NC, Hernandez-Calleros J, Tellez-Avila FI, Torre A, Uribe M. Image-guided percutaneous procedure plus metronidazole versus metronidazole alone for uncomplicated amoebic liver abscess. Cochrane Database Syst Rev. 2009:1.

107. Quaderi M, Rahman MS, Rahman A, Islam N. Amoebic liver abscess and clinical experiences with tinidazole in Bangladesh. J Trop Med Hyg. 1978; 81(1):16-9.

108. Lasserre R, Jaroonvesama N, Kurathong S, Soh C-T. Single-day drug treatment of amebic liver abscess. Am J Trop Med Hyg. 1983;32(4):723-6.

109. Showler AJ, Boggild AK. Entamoeba histolytica. CMAJ. 2013:185(12):1064.

110. Gonzales MLM, Dans LF, Sio-Aguilar J. Antiamoebic drugs for treating amoebic colitis. Cochrane Database Syst Rev. 2019;1.

111. Adams E, MacLEOD I. I. Amebic dysentery and its complications. Medicine. 1977:56(4):315-24

112. Akhondi H, Sabih DE. Liver Abscess. StatPearls [Internet]: StatPearls Publishing; 2019.

113. Dutta A, Bandyopadhyay S. Management of liver abscess. Medicine. 2012;22: 469-75.

114. Jha AK, Das A, Chowdhury F, Biswas MR, Prasad SK, Chattopadhyay S. Clinicopathological study and management of liver abscess in a tertiary care center. J Nat Sci Biol Med. 2015:6(1):71

115. Thompson JE Jr, Forlenza S, Verma R. Amebic liver abscess: a therapeutic approach. Rev Infect Dis. 1985;7(2):171-9.

116. Sherlock S, Dooley J. Diseases of the liver and biliary system: Wiley online library; 2002.

117. Kulhari M, Mandia R. Prospective randomized comparative study of pigtail catheter drainage versus percutaneous needle aspiration in treatment of liver abscess. ANZ J Surg. 2019;89(3):E81-E6. 
118. Kapadia S, Duttaroy D, Ghodgaonkar P, Maru S. Percutaneous catheter drainage of liver abscesses. Int J Surg. 2002;64(6):516-9.

119. Singh O, Gupta S, Moses S, Jain DK. Comparative study of catheter drainage and needle aspiration in management of large liver abscesses. Indian J Gastroenterol. 2009;28(3):88.

120. Ghosh J, Kujur S, Pant P, Kujur R. IDDF2019-ABS-0244 Percutaneous needle aspiration vs. pigtail catheter drainage in amoebic liver abscess: report from a single centre in mining area of india. Gut. 2019;69:A151.

121. Zerem E, Hadzic A. Sonographically guided percutaneous catheter drainage versus needle aspiration in the management of pyogenic liver abscess. Am J Roentgenol. 2007;189(3):W138-W42.

122. Cai YL, Xiong XZ, Lu J, Cheng Y, Yang C, Lin YX, et al. Percutaneous needle aspiration versus catheter drainage in the management of liver abscess: a systematic review and meta-analysis. HPB (Oxford). 2015;17(3):195-201.

123. Baek SY, Lee M, Cho KS, Lee SC, Sung K, Auh YH. Therapeutic percutaneous aspiration of hepatic abscesses: effectiveness in 25 patients. AJR Am J Roentgenol. 1993;160(4):799-802.

124. Ravdin Jl. Amebiasis. Clin Infect Dis. 1995;20(6):1453-64

125. Johnson SA. The cost of war on public health: an exploratory method for understanding the impact of conflict on public health in Sri Lanka. PLoS One. 2017;12(1):e0166674.

126. Nagai M, Abraham S, Okamoto M, Kita E, Aoyama A. Reconstruction of health service systems in the post-conflict Northern Province in Sri Lanka. Health Policy. 2007;83(1):84-93.

127. Shirley DAT, Farr L, Watanabe K, Moonah S. A review of the global burden, new diagnostics, and current therapeutics for amebiasis. Open Forum Infect Dis. 2018;5(7):ofy161.

128. World Health Organization (WHO). Five keys to safer food manual. WHO Department of Food Safety, Zoonoses and Foodborne Diseases. Geneva, Switzerland: WHO Press; 2006. Retrieved from: https://www.who.int/ foodsafety/publications/consumer/manual_keys.pdf. Accessed: 15 Nov 2019

129. World Health Organization (WHO). Guidelines for drinking-water quality: fourth edition incorporating first addendum, 4th ed. World Health Organization. Retrieved from: https://apps.who.int/iris/handle/10665/254637. Accessed: 15 Nov 2019.

130. Babor TF. Public health science and the global strategy on alcohol. Bull World Health Organ. 2010;88(9):643.

\section{Publisher's Note}

Springer Nature remains neutral with regard to jurisdictional claims in published maps and institutional affiliations.

Ready to submit your research? Choose BMC and benefit from:

- fast, convenient online submission

- thorough peer review by experienced researchers in your field

- rapid publication on acceptance

- support for research data, including large and complex data types

- gold Open Access which fosters wider collaboration and increased citations

- maximum visibility for your research: over $100 \mathrm{M}$ website views per year

At BMC, research is always in progress.

Learn more biomedcentral.com/submissions 